\title{
11
}

\section{Implementing Process-Oriented Supply-Chains in a Logistics Game}

\author{
K. Schierholt, D. Brütsch \\ Institute of Industrial Engineering and Management (BWI) \\ Group of Prof. Dr. P. Schönsleben \\ Swiss Federal Institute of Technology (ETH) Zürich \\ Zürichbergstrasse 18, CH 8028 Zürich, Switzerland \\ Tel.: ++4116320524, ++4116320532 \\ Fax: ++4116321040 \\ E-Mail: \{Schierholt,Brutsch\}@bwi.bepr.ethz.ch
}

\begin{abstract}
This paper describes experiences with the use of a production simulation game as part of the course "Logistics and Operational Management" at the Swiss Federal Institute of Technology (ETH) Zürich. After a short introduction to the context in which the game is used and a description of the game itself, the results are presented and discussed. Even though the students have a similar background when starting the game, the results are very different. In the final section, the results and actions taken by the players during the game are interpreted from a logistics point of view. A consequent process organization was not implemented by any of the groups. Still, very interesting and good improvements have been achieved.
\end{abstract}

\section{Keywords}

Process organization, logistics games, supply chain management experiences with students 


\section{CONTEXT AND USE OF THE GAME}

The Institute of Industrial Engineering and Management (BWI), part of the department of Industrial Management and Manufacturing Engineering at the Swiss Federal Institute of Technology ETH Zürich, is an industry-oriented academic institute. The research group of Prof. Dr. Paul Schönsleben covers the areas of Logistics, Production Planning and Control, Information Management and Total Quality Management. The vast majority of research projects in the research group are performed in collaboration with the industry. Many of these projects deal with the improvements of logistics processes within and between industrial companies.

On the other hand, the above mentioned topics are also covered in courses offered for ETH students. About half of the students are full-time students. They study two years in one of the engineering departments (Mechanical, Chemical, Computer or Electrical Engineering) before they join the Department of Industrial Management and Manufacturing Engineering. $3 \frac{1}{2}$ years later (including $1 \frac{1}{2}$ years in industry) they will receive their Masters degree. The other students are part-time students and have already achieved a masters degree at the ETH. They have usually also spent some years in industry. They receive their second degree after two years of part-time studies (including $1 / 2$ year in industry).

The two semester course "Logistics and Operational Management" is the core of the teaching activities in the field of production management and is required for all students. Its main objective is to teach how to optimize logistics processes with the help of a process oriented systemic approach. It covers all subjects of production management from the design of process organizations and customer demand prediction to Just-in-Time principles and multiple-variant manufacturing issues (Schönsleben, 1997).

Since 1993, the Logistics game is played as part of the course in the very first lecture. It is very important, that, at this point of their studies, the students have almost no prior knowledge learned at university level on the subject of logistics. Of course, part-time students in particular but also some of the full-time students have work experience through earlier jobs or internships. Still, a structured introduction to this subject has been given to only few of them. The great advantage of playing this game before learning the background is to have students that are unprejudiced and more imaginative with the subject. They don't stick to principles that they have learned but rather try using common sense to find new solutions to the given problem. Still, as it will be described later, there is a difference in the results of students with and without prior industry experience.

Besides being part of the "Logistics and operational Management" course, the game has also been used for training in workshops of industry projects to promote process orientation and process thinking. Even though it is a manufacturing simulation game, the game was very welcomed and introduced fruitful discussions in projects with service sector companies as well. 


\section{THE GAME}

\subsection{Game structure}

The game simulates the production process in a mass production manufacturing company producing only one product. The initial layout of the factory is shown in Figure 1. Four workers are needed to assemble the product. Every worker has his own table with a storage for incoming parts or modules, a storage for outgoing modules, and working instructions on how to perform his work. The product is made out of toy bricks which can be stuck together in different ways. After the final assembly, the product is transported to the quality control. In the case of possible mistakes, the product is handed over to the reworking which has to correct the production errors and eventually needs to rebuild parts or the complete product. If the quality control is satisfied, the product is moved to the finished products stock. The shipping department is then responsible for fulfilling the customer orders and sending the products to the customer through the external carrier.

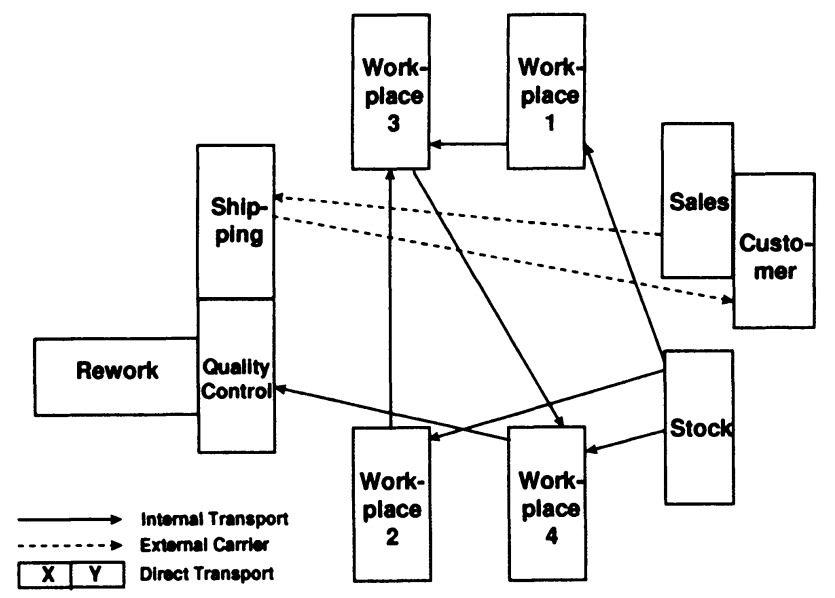

Figure 1: Initial layout of the production

The contact to the customer is maintained only through the sales person which receives the orders directly from the customer, and by the external carrier that delivers the ordered products. The external carrier is also responsible for all transports of order forms from the sales person to the shipping department. All transports of parts, modules and final products from the stock via the workplace to the shipping department are performed by the internal transport service. The number of employees that are directly involved in the production and order processing process, adds up to 12: four workers, one quality controller, one reworker, one sales person, one shipping responsible, one stock manager, two internal transport persons, and one external carrier. 
Besides these employees there are two non-productive persons involved to observe the manufacturing process and work out suggestions for improvements: the general manager and the production engineer.

The moderator of the game play the role of the customer. In regular intervals, a (from the production company point of view) unpredictable number of products is ordered. The delivered products have to be checked on their correctness by the customer. Falsely assembled products are eventually rejected or rather reordered. The initial process structure of the production and the order processing is shown in Figure 2.

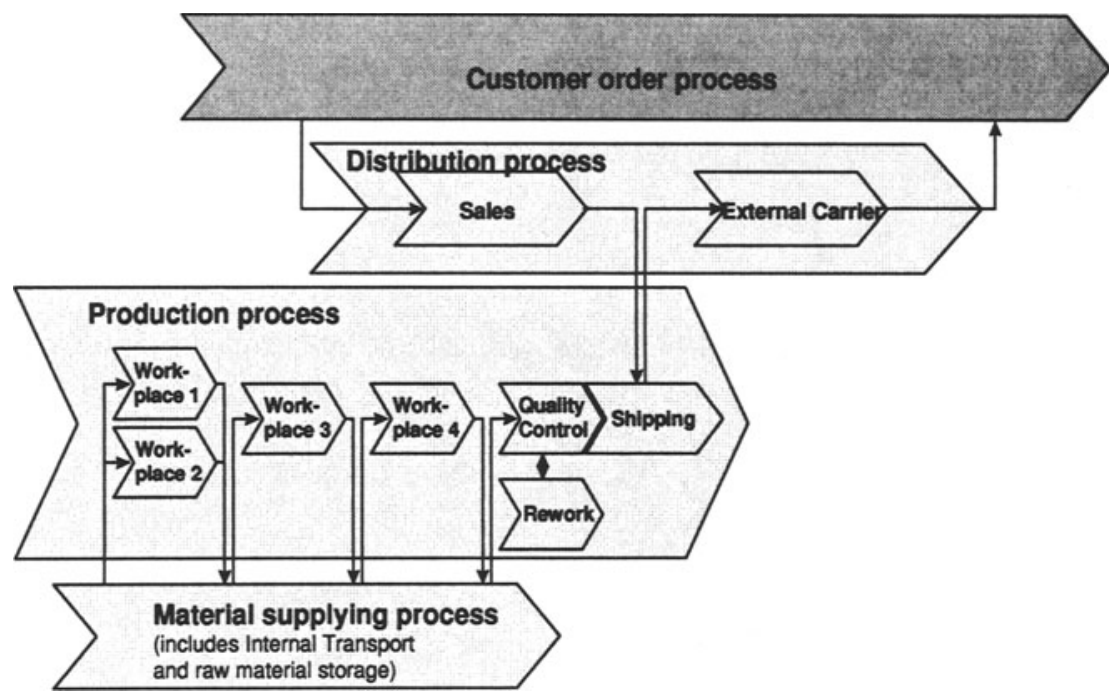

Figure 2: Initial Process structure of the production and the order processing

The production structure at the beginning of the game shows a very oldfashioned, Tayloristic production scheme. The customer contact is only used for determining the necessary quantity of orders to be shipped. Customer information does not provide any input to the production planning process itself. This push system produces independently of customer orders and the final products stock inventory level. This situation is worsened by an unorganized layout and batch sizes that are not harmonized between the work places. It is assumed that very specialized workers perform the given tasks. They only have instructions to perform their own work. Mistakes can only be corrected by the reworking. Communication between the workers is kept at a minimum. Only the communication between the workers and the internal transport service is allowed. 


\subsection{Playing the game}

The game simulates the production over four to six years, where every year is simulated in one game period. In every game period, a number of orders are passed from the customer to the sales person in one minute intervals (one month intervals of simulation time). The number of ordered products varies and is usually kept quite low in the first game period to allow the production to start up. Products have to be delivered after 30 seconds. Late shipments are not accepted. Products are then checked on their correctness. The difference between the number of ordered products and the number of good products is added to the next order.

After ten to twelve orders, the production is stopped and the present state of the product is evaluated. Several factors contribute to the performance measurement. The values are determined and then transformed into cost such that an average price per product can be calculated. The factors can be divided into those that are almost constant over the game period and therefore independent of the number of ordered products in a given game period (and of the number of orders) and those that are related to the number of ordered products. The former consists of personnel cost (100 Units per productive worker, where the General Manager and the Production Engineer are not counted as productive personnel), and the cost for the storage of parts (5 Units), modules (20 Units) and finished products ( 50 Units). The variable cost describe quality and delivery ability aspects. Each incorrect product is counted with 100 Units and 50 Units are charged per product and period of late deliveries.

After the evaluation the group of students will get together and discuss their experiences of the last game period. The general manager moderates this discussion. The goal of the workshop is to find weak points in the production process and measures for improving those. These actions can range from changing the batch size or the layout to dismissing employees or introducing new organizational concepts such as group work. The group does not have a catalog of possible actions; they are almost absolutely free in what they may change. The only things that may not be changed are the product itself, the market structure (introducing more customers), and decisions on whether or not to source out parts of the production. In addition, due to a limited budget for restructuring measures, they are allowed to implement only two measures after each game period. 


\section{RESULTS OF SELECTED GROUPS}

In this section, the results of some groups are described and compared. Results of both, full-time and part-time student groups are shown. About eight groups play the game every year within the course "Logistics and Operational Management". Three groups of the past two years are analyzed thoroughly in the next sections.

\subsection{Final Layouts and final process structures}

The production site layout at the end of the game varied greatly between the different groups. Some groups reorganized almost every part of the production while others only changed details of the layout. Figure 3 shows the initial layout (as in Figure 1) and the final layouts of the three groups that are further analyzed in this section. Again, dotted lines represent transports by the external carrier while full lines show transports of the internal transport service.

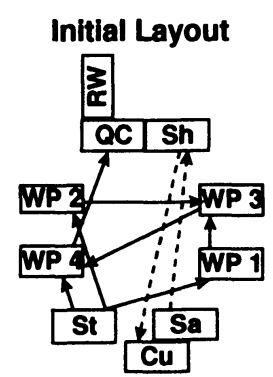

Logend:

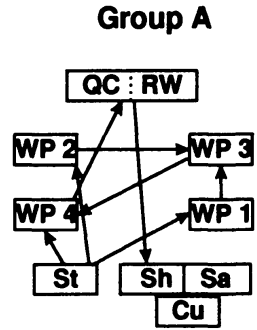

Cu: Customer

Gr: Group

Sa: Sales

Sh: shipping
QC: Quality Control

RW: Reworking

St: Storage

WP: Work Place
Group B
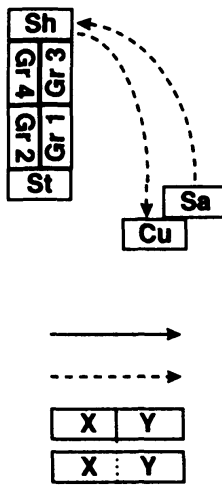

Group C

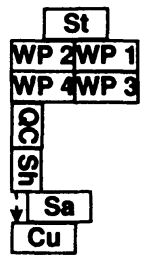

Internal Transport

External Carrier

Direct Transport

Combined Tasks

Figure 3: Layouts of the initial situation and final layouts of three selected groups

The initial situation is quite complex (see Figure 3, Initial Layout) and not oriented towards the customer. Some of the groups realize this problem and are willing to radically change the layout and the processes and to fully adjust to a customer-focused production scheme (see Figure 3, Group C). As a consequence, the position all working places are restructured and the stock is decentralized such that every worker has a stock of the parts the he needs for performing his task. It further implies that instead of using an internal transport service, the modules have to be passed on directly to the next worker in the production process. About one quarter of the examined groups made this radical move. Most other groups tried to find some kind of a middle course. Group B, for example, developed a layout in a U-Structure. Still, one has to consider that the groups have much freedom on which 
measures and changes they want to implement. Only in few cases, the ideas of planned changes go beyond what is allowed. Some groups perform only marginal changes in their layout and production process throughout the whole game. The material flow in Group A is almost similar to the original situation. Only the quality control and the external carrier service were locally optimized.

Usually, the process structure is optimized by the groups during the game. The most important step in this context is the elimination of the internal transports. The modules and final products are moved from one work place to the other directly. Also the transport from the stock to the work places is often removed by introducing decentralized raw material stocks at every working place. The employees that used to do the transport jobs are either retrained to help out in bottleneck tasks or dismissed. It is interesting that the function of the sales person, whose job it is just to receive the customer order and to transmit it to the shipping department, is never questioned. The customer could send his orders directly to the shipping department and the sales position would become obsolete. Very often, steps are taken to improve the communication between the workers and to enhance the information flow as a precondition to a better production planning. But even if communication improvement is not taken as one of the measures, the communication between the workers and between workers and other members of the production team changes during the game. The discussion between the first and the second period usually brings up the question on how to better coordinate the group activities. Such discussions increase the sensibility towards certain issues and thus change the behavior of the workers.

One crucial aspect is recognized only rarely: The initial production process is an instantiation of the push-principle. Products are manufactured without really knowing how many products the customer will finally order. Only few groups realize that by introducing a demand-oriented, flexible production they can fulfill the customer orders exactly without high amounts of work in process and an overloaded finished products storage. Of course, this requires a relatively short production cycle time (Just In Time production), but usually in the second or third game period the production is good enough to handle this task.

\subsection{Measures implemented by the groups}

At the end of every game period, an evaluation of the present production situation is done as described in section 2.2 and decisions about changes are made. Figure 4 shows a statistic of the measures taken and the percentage of groups that implemented these measures.

Even though only little was known on the subject of logistics all but one group harmonized the production by introducing a unified batch size of 1 . This step is implemented much easier in a game environment than in a real manufacturing process but is shows that the underlying idea of having small and flexible batch sizes is understood quickly. More than $85 \%$ of the groups also changed the 
production layout to improve the material flow. Considering the complex and nontransparent original layout, this is not surprising.

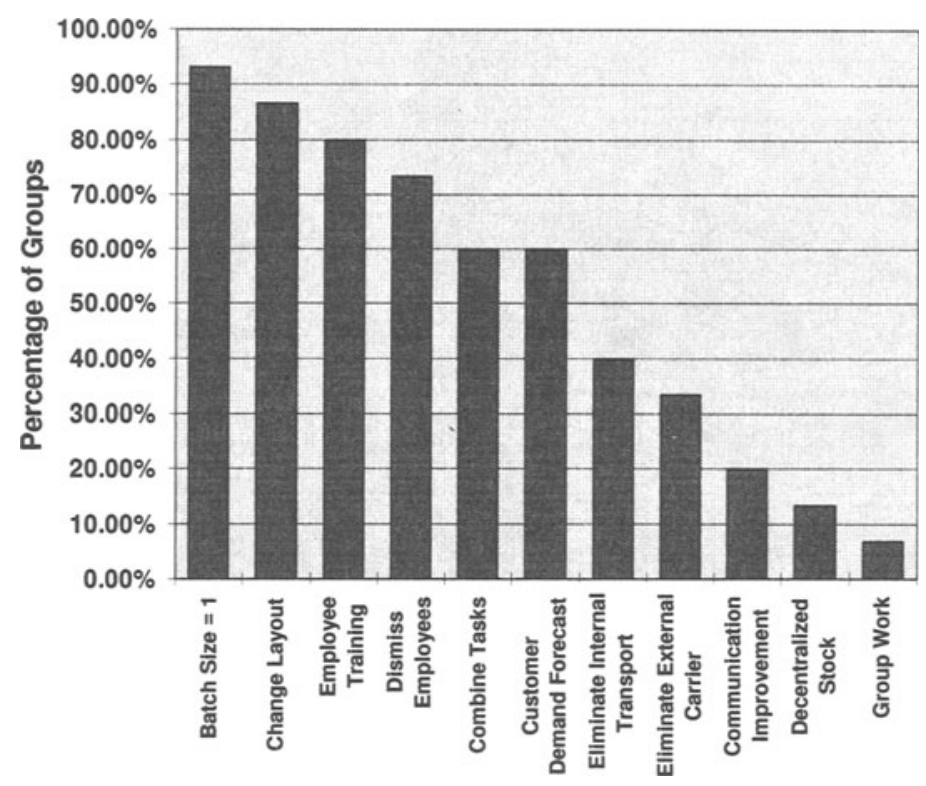

Figure 4: Percentage of Groups implementing measures (over 15 games)

Other measures that are introduced by the majority of the groups are part of the personnel management. Due to severe quality problems in the beginning, much effort is spent in training of employees either to do their job better, to learn new tasks that are performed in addition to their prior work, or to learn new jobs, f.e. to help out at bottleneck tasks. Usually, the learning curve, the experience and the production speed grows so fast that after the second round employees are rather dismissed than retrained for new positions (except for the learning of jobs of dismissed personnel).

A measure that is not directly an optimization of internal processes is the request for customer forecasts for future demands. With every order, the customer will also tell the probable order size for the next period, which can be up to $20 \%$ off the exact value. About two thirds of the groups figured that only an internal optimization is not enough to reduce the work in process. Additional information from the customer was needed to improve production planning and delivery flexibility.

Only in remarkably few cases, totally new organizational concepts as team work are tried. Usually, the material flow is optimized, some task are combined or eliminated, or the stock is decentralized. The strong division of labor in the 
production is still maintained. Still, many of the major problems are realized and attacked by the various measures which becomes obvious in the comparing performance evaluation done in the following section.

\subsection{Development of performance measurement figures}

Measuring the performance is done by evaluating certain factors as already described in section 2.2. This allows to map the successes of the measures taken over the game periods and also is an instrument for comparing the different groups. The fix cost cover personnel cost and costs of the work in process which are almost constant over the game period. Variable cost cover costs emerging from incorrectly assembled products and late deliveries which are averaged over the number of ordered products. The following Figure 5 shows that, in general, a strong decrease of cost is achieved by all groups.

Usually, the variable costs are very high in the beginning. For Group B, the variable costs amounts to almost $90 \%$ of the total cost in the first period. These high costs result from severe quality problems and difficulties mastering the production cycle time. Therefore, training measures and quality discussions are among the first taken by almost every group after the first period.

\section{Fix Cost (independent of the ordered quantity)}

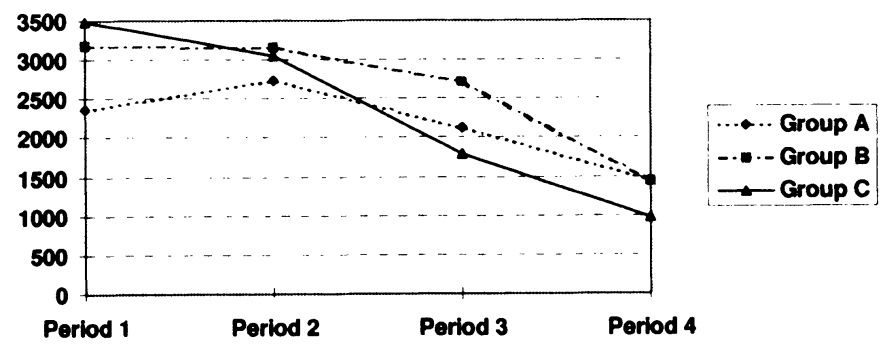

Variable Cost (related to the ordered quantity)

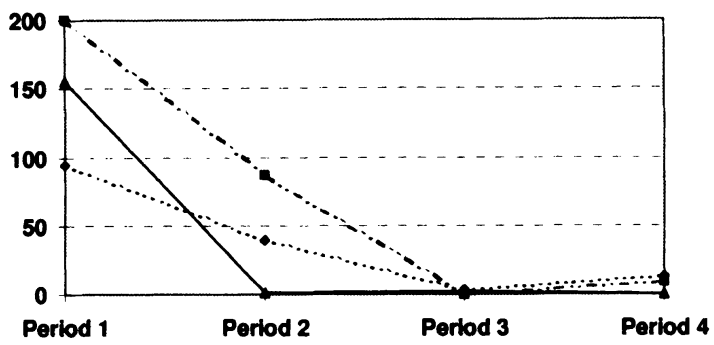

Figure 5: Performance development of selected groups 
After the second round, the variable costs decrease enormously, which is partly due to the measures taken but also a result of the growing experience and comfort with the product and the game. As soon as the quality and delivery problems are almost solved, the groups realize that they have a huge amount of fix costs that is mainly caused by an inefficient material flow. Usually, these problems are attacked starting after the second period but smaller reductions are realized until the end of the game. In contrary to quality problems where the measures to be taken are quite obvious, it is difficult for the students to find ways to reduce the work in process, the finished products stock, and the personnel cost effectively. Group A, as an example, reduced the batch size to 1 after the first period (see Table 1). Still, the fix costs did not decrease but increased. In the given case, the better production and the reduced cycle time filled the finished products stock even faster. The change of the batch size cannot be taken as a stand alone measure but must go along with a change in the production control, as, for instance, a demand-oriented production scheme.

Table 1: Measures implemented by three selected groups

\begin{tabular}{|l|c|c|c|}
\hline Measures Taken (selection) & Group A & Group B & Group C \\
\hline Batch Size =1 & Period 1 & Period 3 & Period 1 \\
\hline Change Layout & & Period 2 & Period 1 and 2 \\
\hline Employee Training & & Period 1 & \\
\hline Dismiss Employees & $\begin{array}{c}\text { Period 3 (4 } \\
\text { Emp.) }\end{array}$ & $\begin{array}{c}\text { Period 2 (3 Emp.) } \\
\text { and 3 (2 Emp.) }\end{array}$ \\
\hline Combine Tasks & Period 1, 2, and 3 & Period 2 & Period 3 \\
\hline Customer Demand Forecast & & & \\
\hline Eliminate Internal Transport & & Period 2 & Period 3 \\
\hline Eliminate External Carrier & Period 3 & & \\
\hline Communication Improvement & & & \\
\hline Decentralized Stock & & & \\
\hline Team Work & & Period 3 & \\
\hline Fix Cost in last Period & 1450 & 1445 & 975 \\
\hline Variable Cost per Product & 13 & 9 & 0 \\
\hline Average Cost per Product & 26 & 27 & 12 \\
\hline Productive Employees & 12 & 12 & 7 \\
\hline Production Cycle Time & 60 sec. & 50 sec. & 47 sec. \\
\hline
\end{tabular}




\section{INTERPRETATION OF RESULTS FROM A THEORETICAL POINT OF VIEW}

\subsection{Organization aspects}

The Logistics Game is supposed to give to the students an overview over organizational aspects in production. The initial situation is characterized by a functional organization structure (see Section 2.1), as it is still wide spread in industry. Since the beginning of the industrial revolution this has been the dominating organization scheme. Many Small and Medium-size Enterprises use this approach until today (Frese, p. 337). While playing the game, the students learn about possibilities of organizational restructuring and get to know demands for modern organizations.

Table 2 compares functional and process-oriented organizations.

Table 2: Comparison of functional and process oriented organizations (see Osterloh, p. 24)

\begin{tabular}{|c|c|}
\hline Functional Organization & Process Oriented Organization \\
\hline high division of labor & job enlargement \\
many hierarchy levels & lean structures \\
many specialized jobs & holistic, customer-oriented tasks \\
stable, predictable & dynamic, complex, competitive \\
environment & environment \\
\hline
\end{tabular}

One organizational approach that was introduced by Group B as an experiment is the implementation of team work. This concept is implemented in a growing number of enterprises (Ulich, p. 171). Group B consisted mainly of parttime students with prior work experience which wanted to examine the effects of team work in a test case. Many of them never had the chance to experiment with team work in a production task before.

The semi-autonomous teams that were formed in the given case each performed all tasks that were necessary to build the full product. This included not only the work of the original work places one to four but also the quality check as part of the production. It was understood that if every team itself is responsible for the quality of its work, there is no need for a quality control any longer. The shipping accepted the customer orders and distributed the work among the teams. Depending on the size of the order and the working speed and capacity of the respective team they received a below or above average work load. The performance figures (see Figure 5) indicate that a high effort is to be put into training of employees when introducing team work. The product quality decreased in the last period which resulted in higher variable cost. 


\subsection{Process design issues}

Major improvements to the production process are not possible if only the layout structure is considered in the analysis. The great potential for radical improvements can only be utilized by combining layout issues with a thorough analysis and optimization of the elementary processes. The reengineering approach as described in Hammer and Champy (p. 32) is a critical aspect. The task is not only to reorganize and restructure the processes but to question the need of every single elementary process and to define its significance and contribution to an added customer value of the product. Figure 6 shows a vision of an optimized, customerfocused production process.

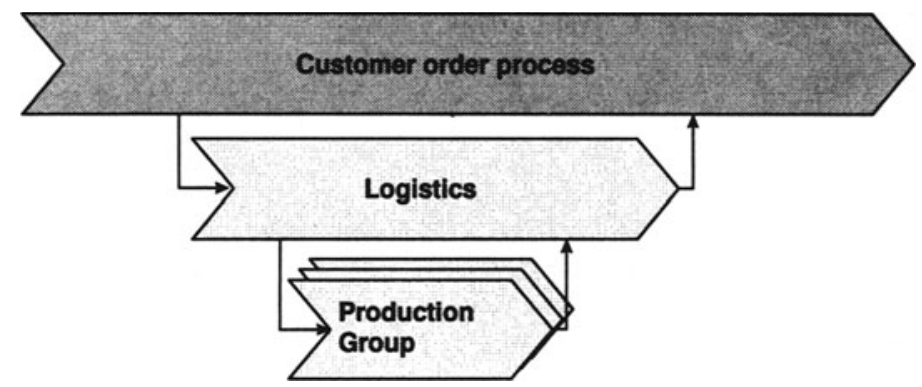

Figure 6: Vision of a process map

Compared to Figure 2, there is now a clear initiation of the logistics process through the customer. No longer will the production produce as much as it thinks the customer will order. Rather, the production speed is a result of the customer orders. It can be seen further that the logistics process receives much importance since this process includes the full control of the production. This aspect of reorganization can be observed in many enterprises today. The position of a supply chain manager who is part of the company management is becoming more common in customer focused companies.

In the example presented in Figure 6 the logistics team is now responsible not only for the material flow but also for the order processing, long and medium term production planning, the distribution of customer orders to the different production teams, and the coordination of the shipping. It is the only point of contact for the customer. The production team uses a decentralized stock and fulfills all tasks including getting the material and the production itself which embeds the quality control. The sales person is no longer needed since the customer corresponds directly with the logistics team. These processes show a very lean organization structure. The production speed is easily scaleable since from the organizational point of view, the number or production teams is not important. They could be added or removed according to long term demand prognoses. 
In order to better demonstrate the improvements in the process design, it is the task of the production engineer to keep track of process changes using a process modeling methodology. Since the students have only little experience with using these methodologies, the optimization of processes with this tool were only partially successful. The ideal case of a process map as displayed in Figure 6 is usually not attained. Still, the process modeling helps to promote a new approach for handling reorganizations and developing leaner and less complex organizations.

\section{CONCLUSIONS}

Learning through games has a great impact on the students. Every group performed successful organizational changes to the initial production structure even though the results were very different. The logistics game teaches not only the possible options that may or may not work in certain situations and gives instant feedback since results of the actions are seen immediately. It also gives a practical introduction into process organization and layout optimization and helps to understand how reorganization can be started and put into practice.

From the teaching point of view, it is important to use easy ways to teach a methodology of process optimization (Hafen and Brütsch). Unfortunately, due to time constraints usually no more than four periods can be played. And there are so many other things to optimize...

\section{REFERENCES}

FRESE, E. (1995): GRUNDLAGEN DER ORGANISATION: KONZEPT - PRINZIPIEN STRUKTUREN. GABLER, WIESBADEN.

HAFEN, U. AND BRÜTSCH, D. (1997): DIE PROZESSORGANISATION WIRD REALITÄT EIN VORGEHENSMODELL FÜR DIE PRAXIS. IN: BLICKWECHSEL BETRIEBSWISSENSCHAFT UND INNOVATION. VDF, ZÜRICH.

HAMMER, M. AND CHAMPY, J. (1993): REENGINEERING THE CORPORATION: A MANIFESTO FOR BUSINESS REVOLUTION. HARPER BUSINESS, NEW YORK.

OSTERlOH, M. (1996): PROZESSMANAGEMENT ALS KERNKOMPETENZ: WIE SIE BUSINESS REENGINEERING STRATEGISCH NUTZEN KÖNNEN. GABLER, WIESBADEN.

SCHÖNSLEBEN, P. (1997): VORLESUNGSSKRIPT ZUR VORLESUNG LOGISTIK UND OPERATIONELLE FÜHRUNG. BWI DER ETH ZÜRICH, ZÜRICH.

ULICH, E. (1994): ARBEITSPSYCHOLOGIE. VDF, ZÜRICH AND SCHÄFFER-POESCHEL, STUTTGART. 